\title{
Training program of general thoracic surgery in Japan: Present status and future tasks
}

Norihiko Ikeda, $\mathrm{MD}, \mathrm{PhD},{ }^{\mathrm{a}}$ Hisao Asamura, $\mathrm{MD}, \mathrm{PhD},{ }^{\mathrm{b}}$ and Masayuki Chida, $\mathrm{MD}, \mathrm{PhD}^{\mathrm{c}}$

\section{BRIEF HISTORY OF GENERAL THORACIC SURGERY IN JAPAN}

The first case of thoracic surgery in Japan involved lung abscess excision by Dr Joh Eguchi in 1903. In 1916, Dr. Kaoru Omi reported his experiences of 28 lung operations, including exploratory thoracotomy for lung cancer, followed by Dr Seiichiro Sato's report of lung tumor operations in $1924^{1}$ and that by Dr Yoshio Ozawa in $1936 .^{2}$

The steady advance was interrupted by World War II. In 1955, Dr Naotsugu Kawai, ${ }^{3}$ Dr Shichiro Ishikawa, ${ }^{4}$ and Dr Kingo Shinoi ${ }^{5}$ presented a special report on the status of lung cancer diagnosis and treatment at the annual meeting of the Japan Surgical Society using data of 1000 lung cancer cases. The clinical practice continued to move forward. The lymph node map developed by Dr Tsuguo Naruke in $1978^{6}$ marked a breakthrough in lung cancer surgery.

Dr Toru Osawa and Dr Sadanobu Seo reported successful operations of esophageal cancers in 1929 and 1932, respectively, marking the first era of esophageal surgery in Japan. ${ }^{7}$ It is conceivable that surgery for lower esophageal cancer was initially performed as an extension of operation for gastric cancer in the cardia. Thus, digestive surgeons, not general thoracic surgeons, have been mainly in charge of esophageal surgery in Japan.

\section{PRESENT STATUS OF GENERAL THORACIC SURGERY IN JAPAN}

A total of 85,307 general thoracic procedures were performed, including $44,140(51.7 \%)$ procedures for primary lung cancer, during $2017^{8}$ (Table 1). The number of lung cancer surgeries has increased continuously (Figure 1).

In Japan, the fair distribution of medical resources has been politically emphasized in the context of the nationwide health insurance system, and the equity of health care

\footnotetext{
From the ${ }^{\mathrm{a}}$ Department of Surgery, Tokyo Medical University, Tokyo, Japan; ${ }^{\mathrm{b}}$ Department of Surgery, Keio University School of Medicine, Tokyo, Japan; and ${ }^{\mathrm{c}}$ Department of General Thoracic Surgery, Dokkyo Medical University, Tochigi, Japan.

Received for publication Aug 11, 2020; revisions received Nov 3, 2020; accepted for publication Nov 23, 2020; available ahead of print Dec 5, 2020.

Address for reprints: Norihiko Ikeda, MD, PhD, Department of Surgery, Tokyo Medical University, 6-7-1 Nishishinjuku, Shinjuku-ku, Tokyo 1600023 Japan (E-mail: ikeda@wd5.so-net.ne.jp).

J Thorac Cardiovasc Surg 2022;163:353-8

$0022-5223 / \$ 36.00$

Copyright (c) 2020 by The American Association for Thoracic Surgery

https://doi.org/10.1016/j.jtcvs.2020.11.137
}

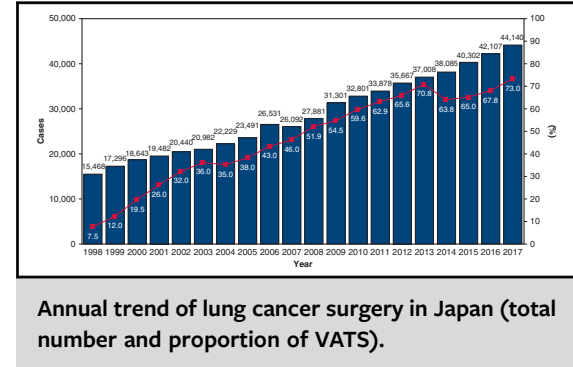

CENTRAL MESSAGE

The Japanese board certification training program for general thoracic surgery develops surgeons with specialized skills and knowledge.

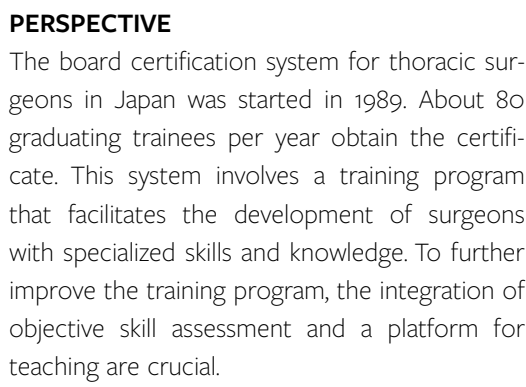

See Commentaries on pages 359 and 360.

services is of international value. ${ }^{9,10}$ Therefore, large general hospitals are expected to be located equally, making the number of educational hospitals larger than that in other countries. ${ }^{11,12}$

\section{FUNDAMENTAL SPECIALTY AREAS AND SUBSPECIALTY AREAS}

Approximately 9000 individuals per year newly acquire a medical degree in Japan. Thereafter, individuals must complete a 2-year initial clinical training by rotating through all major fields of medicine. After completing the entire rotation course, they can choose and apply to their desired specialty from 19 fundamental specialty areas. After completing a 3-year fundamental specialty area training and obtaining the corresponding certificate, trainees can then proceed to subspecialty area training. General surgery falls under the fundamental specialty areas, whereas general 


\section{Abbreviation and Acronym \\ NCD $=$ Japanese National Cancer Database}

thoracic surgery falls under the subspecialty areas. In 2019, a total of 828 new trainees started the General Surgery Training Program and about 120 started the General Thoracic Surgery Program. Trainees complete the General Surgery Training Program at the end of March and take the certificate examination in August. They can begin the General Thoracic Surgery Training Program during April as a presumptive certificated surgeon.

\section{Original Training Program}

The General Surgery Training Program is a 3-year course, and trainees must complete 350 cases of general surgery, including at least 120 cases as an operator. The minimum number of cases that the main operator must experience is fixed by areas: digestive surgery, 50 cases; and cardiovascular surgery, general thoracic surgery, vascular surgery, breast surgery, pediatric surgery, endocrine surgery, and trauma, 10 cases each. ${ }^{13}$ After completing the training program, each trainee receives an evaluation of the completed cases and academic requirements by the local training committee. Personal attitude is also evaluated by a medical team and a final judgment is rendered by the program director. Trainees who pass the evaluation can submit the required documents, including operative records and academic career profile, to the Japan Surgical Society to qualify for examination for General Surgery Certification, which consists of written and oral examinations. After obtaining the General Surgery Certification, the trainees can start their subspecialty area training (eg, general thoracic surgery).

\section{Integrated Training Program}

The surgical techniques in the subspecialty areas have become more specialized and it is important to become familiar with them even in general surgery training. After the end of the first year of the General Surgery Training Program, trainees are allowed to focus on the areas of potential application, if they desire to do so. Trainees can choose the original program if they train in every field equally.

The Integrated Training Program is approved in 5 surgical subspecialties: digestive, cardiovascular, general thoracic, pediatric, and breast. ${ }^{13}$ The first year of the General Surgery Training Program covers the core general surgical contents. The next 2 years provide general surgical as well as general thoracic-focused training. The training itself is flexible based on individual needs and overlaps with the subspecialty training. The Integrated Training Program was started in 2018 and the first graduates are expected in
TABLE 1. Number of cases of general thoracic surgical procedures in Japan during 2017

\begin{tabular}{|c|c|c|}
\hline Procedure & No. of cases & $\%$ \\
\hline Benign pulmonary tumor & 2197 & 2.6 \\
\hline Primary lung cancer & 44,140 & 51.7 \\
\hline Wedge resection & 7009 & \\
\hline Segmental excision & 4685 & \\
\hline Sleeve segmental excision & 14 & \\
\hline Lobectomy & 31,584 & \\
\hline Sleeve lobectomy & 496 & \\
\hline Pneumonectomy & 403 & \\
\hline Sleeve pneumonectomy & 10 & \\
\hline Other bronchoplasty & 33 & \\
\hline Pleuropneumonectomy & 1 & \\
\hline Others & 335 & \\
\hline Other primary malignant pulmonary tumors & 423 & 0.5 \\
\hline Metastatic pulmonary tumor & 8950 & 10.5 \\
\hline Tracheal tumor & 120 & 0.1 \\
\hline Mesothelioma & 698 & 0.8 \\
\hline Chest wall tumor & 691 & 0.8 \\
\hline Mediastinal tumor & 5197 & 6.1 \\
\hline $\begin{array}{l}\text { Thymectomy for myasthenia gravis } \\
\text { without thymoma }\end{array}$ & 189 & 0.2 \\
\hline Inflammatory pulmonary disease & 2423 & 2.8 \\
\hline Empyema & 2962 & 3.5 \\
\hline Bullous disease (not pneumothorax) & 400 & 0.5 \\
\hline Pneumothorax & 14,499 & 17 \\
\hline Chest wall deformity & 193 & 0.2 \\
\hline Diaphragmatic hernia & 28 & 0 \\
\hline Chest trauma & 443 & 0.5 \\
\hline Lung transplantation & 68 & 0.1 \\
\hline Others & 1686 & 2 \\
\hline Total & 85,307 & 100 \\
\hline
\end{tabular}

March 2021. The passing rate of the certificate examination of general surgery will be obtained next year. After completing this program, the trainees should apply for the subspecialty program officially. The general thoracic surgical training is separate from cardiothoracic surgery.

\section{ADMINISTRATION OF THE TRAINING PROGRAM}

The Japanese Medical Specialty Board ${ }^{14}$ was established in 2014 as an independent organization to nurture and certify specialists in fundamental specialty areas and subspecialty areas. General surgery falls under the fundamental specialty areas and unifies 6 subspecialty areas of surgery (ie, digestive, cardiovascular, general thoracic, pediatric, breast, and endocrine). The structure, administration, curriculum, goals and objectives, and accreditation are rigidly defined and founded on the tenets of the Japanese Medical 


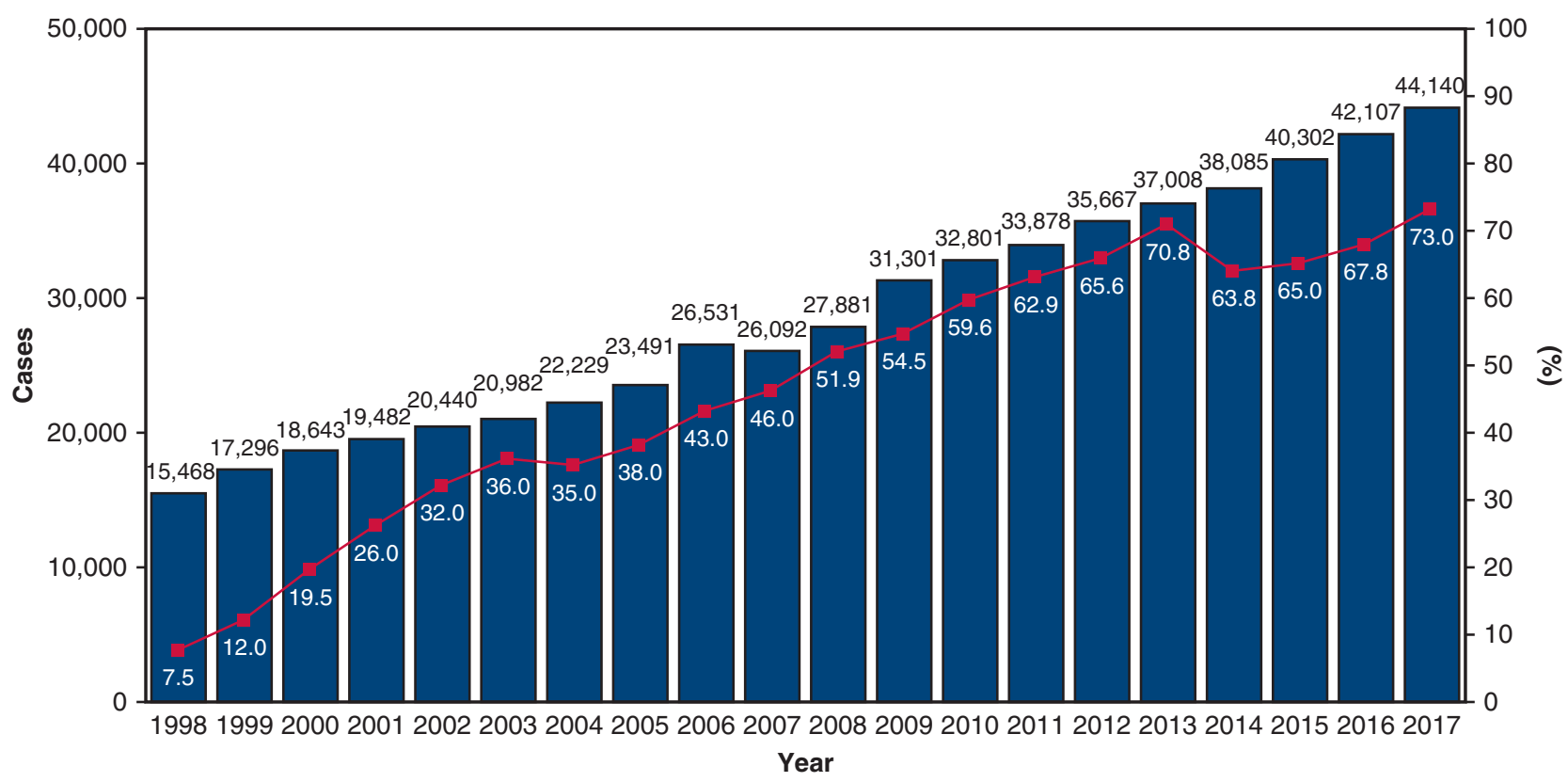

FIGURE 1. Number of cases of lung cancer surgery and the proportion of video-assisted thoracoscopic surgery in Japan from 1998 to 2017. Data from the Japanese Association for Thoracic Surgery (http://www.jpats.org/modules/investigation/index.php?content_id=7).

Specialty Board. The number of trainee positions allowed for each General Surgery Training Program is determined by the Japanese Medical Specialty Board and Japan Surgical Society based on an official assessment of parameters that include case volume, number of academic surgeons, and population of the prefecture for the facility. The fundamental specialty areas have a nationwide matching program, but the matching is independently managed by each main training facility (described later) in the subspecialty areas.

\section{GENERAL THORACIC SURGERY TRAINING PROGRAM STRUCTURE}

The board certification system for thoracic surgeons was started in 1989 by the Japanese Association for Chest Surgery, which has been succeeded by the Japanese Board of General Thoracic Surgery. ${ }^{15}$ The training program should be made according to the model curriculum developed by the Japanese Board of General Thoracic Surgery, which is also approved by the Japanese Medical Specialty Board.

The certified training hospital is classified into the main training facility (180 sites) and the partner training facility. The number of general thoracic operations per year should be more than 150 in the main training facility and more than 25 in the partner training facility. ${ }^{15}$ The trainee belongs to the main training facility and rotates to affiliated partner training facilities (Table 2). The number of trainee positions allowed in each facility is determined by the case volume, and the standard number of operations for 1 trainee is 150 operations per year. ${ }^{15}$

\section{CLINICAL REQUIREMENTS}

The duration of the original General Thoracic Surgery Training Program is 3 years. The trainees who have completed the Integrated Training Program during the General Surgery Training Program can complete the General Thoracic Surgery Training Program in $<3$ years if all the requirements are fulfilled and permitted by the local training committee.

The required operations and their minimum numbers are shown in Table 3. The required operations are classified into general procedures and complicated procedures. The minimum number of cases required is 60 cases as an operator and 120 cases as an assistant, and detailed requirements must be fulfilled. ${ }^{15}$ Notably, the graduating trainees have acquired far more surgical experience than the minimum requirement. Their average in 2019 was 384 cases; that is, 106.8 cases as an operator and 277.2 cases as an assistant.

Trainees can also opt to apply for a 3-month cardiothoracic surgery training during the General Thoracic Surgery Program (Table 2). Extra work for trainees is restricted to $<1860$ hours (960 hours from 2024) in a year and 100 hours in a month. ${ }^{16}$

\section{Japanese National Clinical Database}

All operative records should be registered to an Internetbased data collection system of the Japanese National Clinical Database (NCD). The entry of data for surgical cases was started January 1, 2011. The NCD is a nationwide collaboration with the Japanese Surgical Board Certification System, in which the data of 1.6 million surgical 
TABLE 2. Program elements

\begin{tabular}{|c|c|}
\hline Element & Result \\
\hline No. of training programs & 180 \\
\hline No. of trainees per year & $90-120$ \\
\hline $\begin{array}{l}\text { Prerequisite training } \\
\text { for entry }\end{array}$ & $\begin{array}{l}\text { General surgery }(3 \mathrm{y}) \\
\text { General surgery }+ \text { integrated training } \\
\text { program }(3 \mathrm{y})\end{array}$ \\
\hline Governing body & Japanese Board of General Thoracic Surgery \\
\hline Tenets of training & $\begin{array}{l}\text { Basic knowledge, patient care } \\
\text { Operative skill, research activity } \\
\text { Nontechnical skills (communication, } \\
\text { collaboration, ethics) }\end{array}$ \\
\hline First year & $\begin{array}{l}\text { Demonstration of competence in in-hospital } \\
\text { patient management and postoperative } \\
\text { care } \\
\text { Acquisition of skills in emergency } \\
\text { procedures } \\
\text { Development of skills in making a diagnosis, } \\
\text { including bronchoscopic diagnosis } \\
\text { Acquisition of basic surgical techniques }\end{array}$ \\
\hline Second year & $\begin{array}{l}\text { Accumulation of surgical experience } \\
\text { (operator in low-difficulty-level } \\
\text { procedures) } \\
\text { Presentation in scientific conference }\end{array}$ \\
\hline Third year & $\begin{array}{l}\text { Accumulation of surgical experience } \\
\quad \text { (operator in medium-difficulty-level } \\
\text { procedures) } \\
\text { Presentation in scientific conference } \\
\text { Exposure to clinical trials } \\
\text { Opportunities to conduct basic research } \\
\quad \text { (applicant) }\end{array}$ \\
\hline Program & $3 \mathrm{y}$ \\
\hline Rotations & Varies by program \\
\hline $\begin{array}{l}\text { 3-mo Cardiothoracic } \\
\text { surgical training } \\
\text { (optional) }\end{array}$ & $\begin{array}{l}\text { To understand the anatomy of the heart and } \\
\text { great vessels } \\
\text { To gain proficiency in risk management of } \\
\text { general thoracic operation } \\
\text { To practice vessel anastomosis } \\
\text { To enhance the management of } \\
\text { extracorporeal circulation and } \\
\text { percutaneous cardiopulmonary support }\end{array}$ \\
\hline Certification & $\begin{array}{l}\text { Minimum operative requirement } \\
\text { Academic requirement } \\
\text { Attestation of local program committee } \\
\text { Written examination }\end{array}$ \\
\hline
\end{tabular}

procedures from $>4000$ hospitals were collected in 2014. ${ }^{15,17}$ The data have been used for the authorization of board-certified surgeons of subspecialty surgical societies and the Japan Surgical Society. ${ }^{17,18}$ They systematically collect verified data as common items and specific items in each subspecialty field to conduct clinical research using this large database. ${ }^{18-20}$ The registered data are referred to the board certification system for general thoracic surgery by the Japanese Board of General Thoracic Surgery. ${ }^{19,20}$

\section{ACADEMIC REQUIREMENTS}

The academic requirements for the completion of the program are shown in Table $4 .{ }^{15}$ The trainees are required to publish at least 3 scientific articles as 1 of the authors, with at least 1 of these as first author.

Attendance and presentations at the major annual congress are regulated. Participation in a video-assisted thoracoscopic surgery seminar (ie, simulation training and lecture) and other seminars is necessary to complete the course. However, it has not been verified whether participation in seminars has increased the frequency of thoracoscopic surgery.

\section{CERTIFICATION}

The training program is completed in March and trainees submit the required documents (eg, operative records and certificates of academic requirements) by August. The trainees can extract their operative records from the NCD data and also submit all copies of their operative records as an operator, and copies of 10 operations as an assistant. The examiners check these operative findings to confirm that the operations were performed properly and that they coincide with data obtained from NCD. If these documents are appropriate, the trainees are eligible to take the certificate examination in November. The graduates usually work for the training facility from the time of graduation until the passage of certificate examination. In-service examination in the training facility is not common, but the textbook edited by the Japanese Association of Chest Surgery is an important reference.

The examination consists of a written examination with 90 multiple-choice questions. Because notification of the trainee registry to the Japanese Board of General Thoracic Surgery is not necessary, accurate graduation and attrition rates cannot be obtained, unfortunately. The average numbers of certificate examinees were 95.6 (range, 87111) (2015-2019), 98.4 (2010-2014), and 89 (2005-2009) with no significant changes. The passing rate ranged from $68.4 \%$ to $81.5 \%$ (average, $75.2 \%$ ) between 2003 and 2019. Those who pass the examination receive the General Thoracic Surgery Specialty Certification.

\section{CHALLENGES FOR THE FUTURE TASK}

The term surgical specialist has 2 meanings: a surgeon with a high degree of knowledge, skills, and ethics; and a surgeon with postgraduate clinical training. In the Western medical specialist system, these 2 meanings have been established with almost no distinction. However, it cannot be denied that the latter meaning has been emphasized exclusively in Japan. 
TABLE 3. Required operations

\begin{tabular}{|c|c|c|c|c|c|c|c|c|}
\hline \multirow[b]{2}{*}{ Group } & \multirow[b]{2}{*}{ Subgroup } & \multirow[b]{2}{*}{ Procedure } & \multirow{2}{*}{$\begin{array}{c}\begin{array}{c}\text { Minimum } \\
\text { requirement }\end{array} \\
\text { Operator }\end{array}$} & \multicolumn{5}{|c|}{ Average of graduating trainees during 2019} \\
\hline & & & & $\begin{array}{c}\text { Operator } \\
\text { (thoracotomy) }\end{array}$ & $\begin{array}{l}\text { Operator } \\
\text { (VATS) }\end{array}$ & $\begin{array}{c}\text { Subtotal } \\
\text { (operator) }\end{array}$ & $\begin{array}{c}\text { Subtotal } \\
\text { (assistant) }\end{array}$ & Total \\
\hline \multirow[t]{4}{*}{ A } & $1^{*}$ & Lobectomy/pneumonectomy & 32 & 24 & 23 & 47 & 110 & 157 \\
\hline & 2 & Mediastinal tumor & 3 & 3.5 & 4.8 & 8.3 & 16.9 & 25.2 \\
\hline & 3 & $\begin{array}{l}\text { Spontaneous pneumothorax } \\
\text { Giant bulla }\end{array}$ & 5 & 1.1 & 13.3 & 14.4 & 36.9 & 51.3 \\
\hline & 4 & Partial resection/tumorectomy & 5 & 3.5 & 14.8 & 18.3 & 51.6 & 69.9 \\
\hline \multirow[t]{6}{*}{$\mathrm{B} \dagger$} & 1 & Trachea/bronchoplasty & $5(\mathrm{~B} 1-\mathrm{B} 6)$ & 0.7 & 0 & 0.7 & 2.2 & 2.9 \\
\hline & 2 & Combined resection $\ddagger$ & & 1.6 & 0.2 & 1.8 & 5.5 & 7.3 \\
\hline & 3 & Panpleuro-pneumonectomy & & 0.1 & 0 & 0.1 & 0.9 & 1 \\
\hline & 4 & Segmentectomy & & 2.9 & 4.1 & 8 & 25.6 & 33.6 \\
\hline & 5 & Empyema & & 1.8 & 2 & 3.8 & 8.1 & 11.7 \\
\hline & 6 & Others & & 1.7 & 3.2 & 4.9 & 19.2 & 24.1 \\
\hline \multirow[t]{3}{*}{ Total } & & & & & & 106.8 & 277.2 & 384 \\
\hline & & Operator & Total $\geq 60$ & & & & & \\
\hline & & Assistant & Total $\geq 120$ & & & & & \\
\hline
\end{tabular}

VATS, Video-assisted thoracoscopic surgery. *Mediastinal lymph node dissection $\geq 25$. $\dagger$ Including at least 2 categories and 3 cases from B1-B5. $\ddagger$ Includes chest wall, diaphragm, pericardium, and great vessel.

Therefore, a qualified general thoracic surgeon is expected to be among the staff members of the department, rather than an independent surgeon using his/her own ability. For this reason, the number of operative requirements in Japan is lower than that in the United States and the role of an assistant is also an achievement. In 2018, we increased the minimum numbers of operators and assistants from 50 to 60 and from 100 to 120 , respectively, because an extensive clinical experience would be necessary before becoming an independent surgeon.

\section{Objective Skill Assessment}

In Japan, most surgical training has been conducted as on-the-job training without a structured curriculum for a long period. Although the Japanese Board of General

TABLE 4. Academic requirements

\begin{tabular}{lc}
\hline \multicolumn{1}{c}{ Element } & Minimum requirement \\
\hline Publication & 3 (first or co-author) \\
& 1 first author, necessary \\
Conference presentation & 5 \\
Conference attendance* & 5 \\
Seminar attendance $\dagger$ & 2 \\
VATS seminar participation & 1 \\
Medical safety lecture & 2 \\
\hline
\end{tabular}

VATS, Video-assisted thoracoscopic surgery. *Annual congress of Japanese Association for Chest Surgery or Japanese Association for Thoracic Surgery. †Organized by Japanese Association for Chest Surgery or Japanese Association for Thoracic Surgery.
Thoracic Surgery prescribes the essential requirements for the curricula and contents of training, it does not monitor and enforce compliance as does the Accreditation Council for Graduate Medical Education in the United States. Irrespective of different policies, the effects of daily teaching should be evaluated using an objective rating system. The objective skill assessment is not yet well constructed, and it is hoped that trainees can specifically understand the goals at each level for important skills using visual educational materials. Skill assessment should be substantially strengthened using a validated assessment tool, namely, the Operative Performance Rating System, ${ }^{21}$ which is used by the American Board of Surgery. Therefore, faculty development, including education in teaching, is necessary.

\section{Off-the-Job Training Improvement}

Most of the main training facilities have simulation centers, but only $12.5 \%$ of these facilities use them as part of the routine training program because this is not compulsory, becoming a major barrier to the use of simulation. ${ }^{22} \mathrm{We}$ believe that the Japanese Board of General Thoracic Surgery should make simulation training mandatory and routine by changing the program similarly to North America. ${ }^{11}$ Opportunities for obtaining robotic surgery skills such as in video-assisted thoracoscopic surgery seminars and nontechnical skills such as in conference sessions, as well as seminars and e-learning programs by academic societies should be continuously set up for improving surgical skills. 


\section{Well-being of Trainees and Solutions for Gender Gaps}

The feudal system of surgery has also been improved, and there is an atmosphere of considering the well-being of trainees. As a system, there is a tendency to reduce the burden on doctors and prevent a reduction in their number by regulating working hours and raising nurse practitioners and physician assistants. Confidential mental health consultation is available in every training facility as part of a policy aimed at helping doctors when they experience depression and burnout. Regarding female members of the Japanese Association for Chest Surgery, their number was 211 in 2015 and this increased to 273 in 2020, corresponding to $6.6 \%$ and $8.5 \%$ of all members, respectively. The number of female certified general thoracic surgeons was $40(2.9 \%)$ in 2015 and $76(4.9 \%)$ in 2020 . Because women still play a central role in attending to household chores in Japan, childcare and marriage remain as large barriers to the career development of many female surgeons (childcare, 37.6\%; marriage, $15.9 \%$ ), which differ significantly from the those of male surgeons (childcare, $3.4 \%$; marriage, $1.9 \%)^{23}$

Additional items cited by women were childcare facilities, including sick-child care, followed by flexible work arrangements and re-employment support after maternity leave. ${ }^{23}$ Task shift is accelerating to minimize nonphysician obligations. These initiatives are being actively pursued in most institutions, in part owing to the government's work style reform policy, including the support for women's advancement in society. The Japan Association of Women Surgeons ${ }^{24}$ has played an important role in improving such working conditions.

\section{CONCLUSIONS}

The development of medical specialists with sufficient operative skills appears to achieve favorable outcomes. However, the establishment of an objective evaluation method for achievement level is directly linked to the improvement of the training system. Thus, attention should be paid to making sustained improvements in the training system to improve the training skills of educators, introduce objective assessment of trainees, and promote the wellbeing of trainees, particularly female surgeons.

\section{Conflict of Interest Statement}

The authors reported no conflicts of interest.

The Journal policy requires editors and reviewers to disclose conflicts of interest and to decline handling or reviewing manuscripts for which they may have a conflict of interest. The editors and reviewers of this article have no conflicts of interest.

The authors thank Dr Edward Barroga, St Luke's International University, Tokyo, Japan, for reviewing and editing the manuscript.

\section{References}

1. Fujisawa T. Beginning and development of lung cancer surgery in Japan. Gen Thorac Cardiovasc Surg. 2010;58:387-92.

2. Ozawa Y. Lung resection [in Japanese]. J Japan Surg Soc. 1942;42:1863-944.

3. Kawai N. The present conditions of pulmonary tumors in Japan [in Japanese]. J Japan Surg Soc. 1955;56:659-65.

4. Ishikawa S. Pathology and impaired physiology of lung cancer [in Japanese]. J Japan Surg Soc. 1955;56:667-85.

5. Shinoi K. Diagnosis and differential diagnosis of lung cancer [in Japanese]. J Japan Surg Soc. 1955;56:686-94.

6. Naruke T, Suemasu K, Ishikawa S. Lymph node mapping and curability at various levels of metastasis in resected lung cancer. J Thorac Cardiovasc Surg. $1978 ; 76: 832-9$.

7. Matsubara H. Advances in the surgical treatment of esophageal cancer since 1965. Ann Gastroenterol Surg. 2020;4:243-9.

8. Committee for Scientific Affairs, The Japanese Association for Thoracic Surgery, Shimizu H, Okada M, Tangoku A, Doki Y, Endo S, et al. Thoracic and cardiovascular surgery in Japan during 2017: annual report by the Japanese Association for Thoracic Surgery. Gen Thorac Cardiovasc Surg. 2020;68: 414-9.

9. Ikegami N, Yoo BK, Hashimoto H, Matsumoto M, Ogata H, Babazono A, et al. Japanese universal health coverage: evolution, achievements, and challenges. Lancet. 2011;378:1106-15.

10. Medical Council, Ministry of Health, Labour, and Welfare, Japan [in Japanese]. Available at: https://www.mhlw.go.jp/stf/newpage_04665.html. Accessed December 9, 2020.

11. Schieman C, Seder CW, D’Amico TA, Grondin SC. General thoracic surgical training in North America: contrasting general surgery residencies in Canada and the United States. J Thorac Cardiovasc Surg. 2018;156:2379-87.

12. Park SJ, Kin DJ, Kim JB, Park KH, Lee JW. Cardiothoracic surgery training in South Korea: challenges and new hopes. J Thorac Cardiovasc Surg. 2020;159: 205-14.

13. Japan Surgical Society. Japan Surgical Society specialty system [in Japanese]. Available at: https://www.jssoc.or.jp/procedure/specialist-new/new_index.html. Accessed December 9, 2020.

14. Japanese Medical Specialty Board [in Japanese]. Available at: https://jmsb.or.jp/. Accessed December 9, 2020.

15. The Japanese Board of General Thoracic Surgery [in Japanese]. Available at: http://chest.umin.jp/. Accessed December 9, 2020.

16. Ministry of Health, Labour, and Welfare. Work style reform of medical doctors [in Japanese]. Available at: https://www.mhlw.go.jp/content/10800000/ 000516867.pdf. Accessed December 9, 2020.

17. Miyata H, Gotoh M, Hashimoto H, Motomura N, Murakami A, Tomotaki A, et al. Challenges and prospects of a clinical database linked to the board certification system. Surg Today. 2014;44:1991-9.

18. Gotoh M, Miyata H, Hashimoto H, Wakabayashi G, Konno H, Miyakawa S, et al. National Clinical database feedback implementation for quality improvement of cancer treatment in Japan: from good to great through transparency. Surg Today. 2016;46:38-47.

19. Endo S, Ikeda N, Kondo T, Nakajima J, Kondo H, Yokoi K, et al. Development of an annually updated Japanese National Clinical database for chest surgery in 2014. Gen Thorac Cardiovasc Surg. 2016;64:569-76.

20. Ikeda N, Endo S, Fukuchi E, Nakajima J, Yokoi K, Chida M, et al. Current status of surgery for clinical stage Ia lung cancer in Japan: analysis of the national clinical database. Surg Today. 2020;50:1644-51.

21. Larson JL, Williams RG, Ketchum J, Boehler ML, Dunnington GL. Feasibility, reliability and validity of an operative performance rating system for evaluating surgery residents. Surgery. 2005;138:640-7.

22. Kurashima Y, Watanabe Y, Ebihara Y, Murakami S, Shichinohe T, Hirano S Where do we start? The first survey of surgical residency education in Japan. Am J Surg. 2016;211:405-10.

23. Kawase K, Nomura K, Tominaga R, Iwase H, Ogawa T, Shibasaki I, et al. Analysis of gender-based differences among surgeons in Japan: results of a survey conducted by the Japan Surgical Society. Part. 2: personal life. Surg Today. 2018;48:308-19.

24. Japan Association of Women Surgeons mission and history. Available at: http:// jaws.umin.jp/English.html. Accessed December 9, 2020.

Key Words: general thoracic, board certification system, training 